\title{
O relato testemunhal na cobertura do Jornal Hoje à tragédia de Brumadinho: reflexões a partir dos modos de endereçamento
}

\author{
The testimonial report on the coverage of Jornal Hoje to \\ Brumadinho's dam tragedy: \\ reflections from the addressing modes perspective
}

\section{El relato testimonial en la cobertura de Jornal Hoje sobre la tragedia de Brumadinho: reflexiones desde las formas de abordar}

\author{
Michele Negrini \\ Universidade Federal de Pelotas - RS - Brasil \\ ORCID: https://orcid.org/0000-0003-2999-0186 \\ Endereço Currículo Plataforma Lattes: http://lattes.cnpq.br/9158823819923143 \\ E-mail: mmnegrini@yahoo.com.br \\ Natália Sheikha Redii \\ Universidade Federal de Pelotas - RS - Brasil \\ ORCID: https://orcid.org/0000-0003-1449-1392 \\ Endereço Currículo Plataforma Lattes: http://lattes.cnpq.br/4642349328044463 \\ E-mail: nataliaredu@gmail.com
}

\begin{abstract}
Resumo: O rompimento da barragem de Brumadinho foi uma das maiores tragédias ambientais do Brasil, causando a morte de mais de 200 pessoas e gerando grandes devastações ao meio ambiente. $\mathrm{O}$ evento foi amplamente apresentado nos meios de comunicação e teve grande cobertura dos telejornais. O Jornal Hoje, no dia 26 de janeiro de 2019, apresentou uma edição especial de cobertura ao acontecimento trágico. Desta forma, este artigo tem como foco a observação do papel dos mediadores, no programa Jornal Hoje, na captação do relato testemunhal na tragédia de Brumadinho. Vamos desenvolver o estudo a partir da ótica dos modos de endereçamento, com foco em um dos quatro operadores de análise propostos por Gomes (2007): os mediadores.
\end{abstract}

Palavras-chave: Relato Testemunhal. Mediadores. Modos de Endereçamento. Telejornalismo. Jornal Hoje.

Abstract: The rupture of Brumadinho dam is one of the biggest environmental tragedies in Brazil, that caused more than 200 people's death and a huge nature 


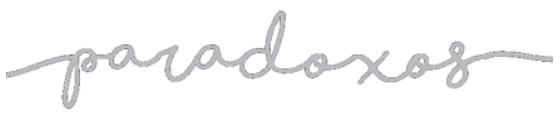

0 relato testemunhal na cobertura

do Jornal Hoje à tragédia de Brumadinho:

reflexões a partir dos modos de endereçamento.

NEGRINI, REDÜ, 2021

devastation. This event were widely covered on the media and at the news. The television newscast Jornal Hoje, from Rede Globo, on 26th january 2019 presented a special edition covering the tragic event. Therefore, this article have focus on notice the Jornal Hoje mediators role on taking testimonial report at the Brumadinho tragedy. We'll develop this study by the perspective of the addressing modes, with focus in one of the four analysis operators proposed by Gomes (2007): the mediators.

Keywords: Testimonial report. Mediators. Addressing mode. Television journalism. Jornal Hoje.

Resumen: La ruptura de la represa Brumadinho fue una de las mayores tragedias ambientales en Brasil, causando la muerte de más de 200 personas y causando una gran devastación al medio ambiente. El evento fue ampliamente presentado en los medios de comunicación y tuvo una gran cobertura en las noticias. Jornal Hoje, el 26 de enero de 2019, presentó una edición especial que cubre el trágico evento. Así, este artículo se centra en la observación del papel de los mediadores, en el programa Jornal Hoje, en la captura del relato testimonial sobre la tragedia de Brumadinho. Desarrollaremos el estudio desde la perspectiva de los modos de direccionamiento, centrándonos en uno de los cuatro operadores de análisis propuestos por Gomes (2007): los mediadores.

Keywords: Informe testimonial. Mediadores. Modos de direccionamiento. Teleperiodismo. Jornal Hoje.

\section{Aspectos introdutórios}

O rompimento da barragem de Brumadinho, no dia 25 de janeiro de 2019, na região metropolitana de Belo Horizonte, foi uma das mais conhecidas tragédias ambientais do cenário brasileiro. Com a invasão da lama à região, houve a destruição de construções e do meio ambiente, ocasionando a morte de mais de 200 pessoas e de um grande número de animais. O rompimento ocorreu na Mina do Feijão, da mineradora Vale.

Os repórteres Felipe Souza e João Fellet, em matéria publicada na Revista Época de 28 de janeiro de 2019, assinalam que a tragédia de Brumadinho pode ser apontada como o maior acidente de trabalho da história do Brasil. Em reportagem de 25 de setembro de 2019, a repórter Renata Evangelista, do portal Hoje em Dia, aponta que na data em que a tragédia completou 8 meses, havia 249 mortos e 21 desaparecidos.

DOI: http://doi.org/10.14393/par-v6n1-2021-55873 - Paradoxos, Uberlândia, v. 6, n. 1, p. 143-159, jan./jun. 2021| 144 


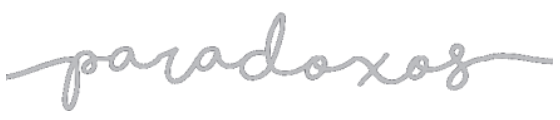

0 relato testemunhal na cobertura

do Jornal Hoje à tragédia de Brumadinho: reflexões a partir dos modos de endereçamento.

NEGRINI, REDÜ, 2021

No dia da tragédia, 25 de janeiro de 2019, e nos dias seguintes, os meios de comunicação fizeram ampla cobertura ao caso, convocando o olhar do público para o ocorrido. No âmbito televisivo, diversos ângulos do fato foram levados aos olhos dos espectadores. E os telejornais acionaram, em seu espaço, diversos aspectos acerca da tragédia, como: o número de mortos e a retirada dos corpos; o resgate dos sobreviventes em meio à lama; a tentativa de explicações sobre o motivo da ocorrência do desastre; e a posição de políticos sobre o ocorrido. A dor dos enlutados foi enfocada e a incerteza dos familiares dos desaparecidos também teve grande ênfase.

O Jornal Hoje fez uma grande cobertura $^{1}$ da tragédia, especialmente na edição de sábado, 26 de janeiro de 2019, que teve mais de duas horas e meia de duração. No dia, o JH foi apresentado por Maria Julia Coutinho, que já começou a edição dando ênfase à tragédia e às vítimas dela. Ainda na escalada ${ }^{2}$, é mostrada a tentativa de retirada de uma mulher dos escombros, gritando de dor e muito abalada, o que aponta para termos uma edição de telejornal com a demonstração de muitas tristezas e de emoções. As grandes proporções da tragédia são reiteradas nas palavras da apresentadora ao finalizar a escalada: "Tudo sobre essa tragédia humana e ambiental agora no Jornal Hoje" (01m:12s). E ela ainda enfatiza a realização da grande cobertura no JH à tragédia quando diz: "O Jornal Hoje deste sábado traz uma cobertura especial sobre a tragédia em Brumadinho, no interior de Minas, depois do rompimento da barragem 1 do complexo da mina do córrego do Feijão" $(01 \mathrm{~m}: 27 \mathrm{~s})$. As palavras da apresentadora sinalizam que o telejornal vai dar grande espaço ao assunto e vai apresentar diversos olhares sobre o caso, assinalando que a edição vai assumir um estilo dotado de emoções e de tristezas.

O papel dos jornalistas é fundamental no contexto da realização de uma cobertura televisiva de tragédia. Nesta seara, Coutinho e Mata (2013) tomam a definição de tragédia a partir de Ted White como sendo uma forma de ocorrência de um desastre em escala menor, com proporções menores e salientam que: "A

\footnotetext{
${ }^{1}$ Emerim e Brasil (2011, p.4; grifo dos autores) refletem sobre grande cobertura: "Assim, uma grande cobertura pode remeter a um tipo de trabalho jornalístico que mostre um acontecimento em todas as suas perspectivas ou, pelo menos, as perspectivas possíveis de ser exibidas em televisão através da função jornalística".

${ }^{2}$ Segundo Thiago Moraes (2015): "Na TV, as manchetes não são escritas na tela, mas narradas de forma a atrair a atenção do telespectador. É aquele momento em que os apresentadores aparecem subitamente dizendo frases impactantes sobre os principais assuntos do telejornal".

DOI: http://doi.org/10.14393/par-v6n1-2021-55873 - Paradoxos, Uberlândia, v. 6, n. 1, p. 143-159, jan./jun. 2021| 145
} 


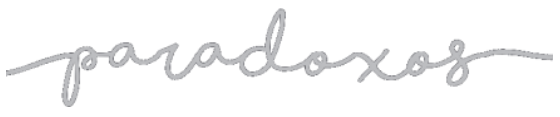

0 relato testemunhal na cobertura

do Jornal Hoje à tragédia de Brumadinho: reflexões a partir dos modos de endereçamento.

NEGRINI, REDÜ, 2021

cobertura de tragédias no telejornalismo tem uma série de características e aspectos merecedores de atenção, seja com relação a questões de ordem técnica, operacional, ética e mesmo estética" (COUTINHO E MATA, 2013, p.381). Eles apontam ainda que, para Ted White (2008), os desastres naturais que originam tragédias são uma oportunidade para as emissoras mostrarem os seus jornalistas mais talentosos, o que infere que Ted sinaliza para a importância de uma cobertura aprofundada e de qualidade para este tipo de vento. Os autores acrescentam:

Os grandes desastres em geral demandam uma cobertura continuada das emissoras de televisão, e por isso também envolvem uma logística diferenciada de produção. Além dos plantões com revezamento de repórteres e transmissões ao vivo, também as estrelas das emissoras integram a equipe em coberturas televisivas que adquirem um caráter de excepcionalidade, e podem render prêmios, ou ao menos indicações (COUTINHO E MATA, 2013, p.383)

Em meio a um ambiente de tragédia, as pessoas com informações sobre o acontecimento se mostram como testemunhas dos fatos e os seus relatos são precípuos para a conformação da narrativa telejornalística, pois faz parte da essência do jornalismo a apresentação de uma reportagem com uma pluralidade de vozes. Motta e Rublescki (2013), referindo-se à tragédia da Kiss, ocorrida em Santa Maria/RS, assinalam que as fontes testemunhais são fundamentais para o processo de apuração do acontecimento, mesmo que tenham características de fragmentação e de emotividade. Já Adriano Duarte Rodrigues (1997, p.1) fala sobre a importância da credibilidade no relato testemunhal:

No testemunho, o destinador possui o privilégio exclusivo de deter o poder de controlar a veracidade da sua mensagem, pelo fato de ter experienciado direta e imediatamente os fenômenos e os acontecimentos que narra. Por essa razão, a credibilidade da mensagem trocada depende exclusivamente do reconhecimento por parte do destinatário do capital de credibilidade que está disposto a atribuir ao destinador da mensagem.

As palavras do pensador português apontam para a importância de uma informação provinda de um relato testemunhal por ter uma demarcação de informações vindas de alguém que tem experiência com o fato contado. $\mathrm{O}$ relato testemunhal deixa a reportagem mais rica em informações e com mais pluralidade. $\mathrm{E}$ 


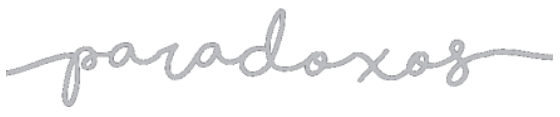

0 relato testemunhal na cobertura

do Jornal Hoje à tragédia de Brumadinho:

reflexões a partir dos modos de endereçamento.

NEGRINI, REDÜ, 2021

cabe destacar que o jornalista tem papel importante na coleta destes relatos, tendo que ter sensibilidade para tratar com a fonte e para colher as informações. Desta forma, este artigo tem como foco a observação do papel dos mediadores (GOMES, 2007), no programa Jornal Hoje, na captação do relato testemunhal na tragédia de Brumadinho. Vamos observar a edição especial do telejornal, que foi ao ar no dia 26 de janeiro. Como a edição teve mais de duas horas de duração, para fins analíticos, vamos nos focar na primeira meia hora do programa.

\section{Discussões sobre o testemunho no telejornalismo}

O testemunho, conforme mencionado acima, constitui uma das fontes jornalísticas utilizada na apuração dos fatos. Contudo, em situações de tragédia, possui um grau de importância diferenciado. Evidente que toda e qualquer situação de tragédia ocorre de maneira inesperada. Com isso, a cobertura dos fatos é feita sem ampla organização prévia. E, em havendo uma situação de caos instaurada diante de uma população que anseia por notícias, não há tempo para aguardar por informações oficiais das autoridades. Por conta disso, “[...] as fontes testemunhais são mais convocadas nos primeiros dias de cobertura" (MOTTA e AMARAL, 2016, p. 78).

Deste modo, neste primeiro momento de cobertura jornalística do acontecimento trágico, a apuração de informações ocorre, justamente, através do testemunho. Assim, o repórter entrevista não só aqueles que presenciaram os fatos, mas também aqueles que sobreviveram à catástrofe. Essa abrangência na coleta dos testemunhos, além de conferir veracidade às notícias veiculadas, também serve como meio de abordar o caráter humano na cobertura das tragédias, propiciando que o telespectador possa sentir empatia com o sofrimento da(s) vítima(s). Afinal, "[...] quem mais poderia ressaltar o aspecto humano inerente a uma cobertura de tragédia, senão as pessoas que viveram esse acontecimento?" (MOTTA e AMARAL, 2016, p. 80-81). É uma aproximação com o telespectador, ao mesmo tempo em que se mantém uma distância segura dos fatos.

Cumpre destacar que além do caráter informativo, os testemunhos igualmente possuem alta carga emocional, o que contribui para um maior apelo perante a audiência.

DOI: http://doi.org/10.14393/par-v6n1-2021-55873 - Paradoxos, Uberlândia, v. 6, n. 1, p. 143-159, jan./jun. 2021| 147 


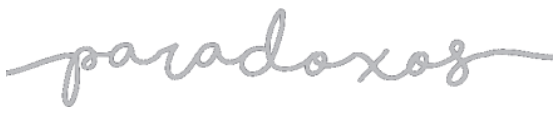

0 relato testemunhal na cobertura

do Jornal Hoje à tragédia de Brumadinho: reflexões a partir dos modos de endereçamento.

NEGRINI, REDÜ, 2021

Neste diapasão, Amaral (2013a, p. 73) afirma que: “[...] as fontes testemunhais descrevem os fatos e trazem a marca do sensível, da experiência, do vivido". Em virtude dessa necessidade de equilíbrio entre informar e emocionar, as pesquisadoras Motta e Amaral (2016, p. 87) prosseguem ressaltando que:

[...] os testemunhos produzem o efeito não só da emoção necessária para ilustrar o sofrimento, mas a possibilidade de provas de verdade que podem esclarecer os aspectos iniciais do fato e, até mesmo, ajudar no apontamento de causas, motivos e consequências da tragédiaainda que não possam fornecer certezas absolutas.

Do exposto, facilmente se constata que o testemunho pode ser visto sob duas perspectivas: 1) da necessidade da testemunha em desabafar e buscar por justiça e 2) da urgência do repórter na reconstituição e esclarecimento dos fatos (MOTTA E AMARAL, 2016, p. 81). Amaral (2013b, p. 184) lembra que:

O acontecimento catastrófico é desorganizador, desestabilizador e cheio de singularidades. Tem aspectos imensuráveis, difíceis de serem relatados por jornalistas e fontes, o que demanda do jornalismo um esquadrinhamento exaustivo.

Assim, também cabe ao jornalista, na apuração dos fatos, “[...] o cruzamento dos testemunhos dos sobreviventes e de outras testemunhas secundárias, usadas de forma a confirmar as versões apresentadas" (MAIA E BARRETO, 2018, p. 215). É de suma relevância destacar que, nas situações de tragédia, por conta de toda a desordem instalada, os relatos testemunhais ocupam grande parte da cobertura, sendo as principais fontes do jornalista. Porém, com o passar do tempo após o acontecimento, diante do mínimo de ordem reconquistada, bem como da prestação de informações pelas fontes/órgãos oficiais, o testemunho vai deixando de ser tão precípuo para a cobertura. Por conta disso, as pesquisadoras Maia e Barreto (2018, p. 217) afirmam que o testemunho deve ser encarado como:

[...] forma de conceber o acontecimento de modo complexo, com suas contradições próprias da disputa de sentidos que está presente no social, o jornalista amplia as possibilidades de compreensão, podendo promover questionamentos [...].

Cumpre lembrar, ainda, que com a retomada do controle da situação, as equipes de TV podem se organizar de forma mais adequada e apresentar, por exemplo, DOI: http://doi.org/10.14393/par-v6n1-2021-55873 - Paradoxos, Uberlândia, v. 6, n. 1, p. 143-159, jan./jun. 2021| 148 


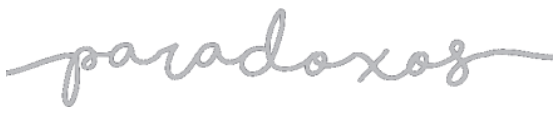

0 relato testemunhal na cobertura

do Jornal Hoje à tragédia de Brumadinho: reflexões a partir dos modos de endereçamento.

NEGRINI, REDÜ, 2021

comentário especializado e investigar, de modo mais profundo, todas as questões que surgem diante de qualquer tragédia.

\section{Modos de endereçamento}

Gomes (2007) assinala que o conceito de modo de endereçamento tem origem na análise fílmica e tem tido ajustes desde os anos 80 para dar suporte a observações sobre como programas televisivos se relacionam com os espectadores.

A pensadora Elizabeth Ellsworth (2001), em suas reflexões sobre modo de endereçamento, destaca que o termo tem um aporte teórico e um peso político: "O modo de endereçamento é um termo dos estudos de cinema, um termo que tem um enorme peso teórico e político. Aprendi sobre ele nas aulas sobre cinema e sobre mudança social. É a isso que ele se resume: quem este filme pensa que você é?” (p.11).

Em suas reflexões, Ellsworth $(2001$, p.12) aponta que teóricos do cinema desenvolveram a perspectiva de modo de endereçamento para tratar, com especificidades do cinema, de algumas questões significativas aos estudos da sétima arte, à crítica da arte e da literatura, à sociologia, à antropologia, à história e a educação.

Essas questões têm a ver com a relação entre o "social" e o "individual". Questões como: "qual é a relação entre o texto de um filme e a experiência do espectador, a estrutura de um romance e a interpretação feita pelo leitor, uma pintura e a emoção da pessoa que a contempla, uma prática social e a identidade cultural, um determinado currículo e sua aprendizagem?". Em outras palavras, qual é a relação entre o lado de "fora" da sociedade e o lado de "dentro" da psique humana?

Tais questões remetem à relação entre um texto e o público, no caso do jornalismo entre o meio e os espectadores. Desta forma, cabe destacar que Ellsworth enfatiza que o termo não se restringe a um momento visual, falado, mas que ele vai além, que é uma estruturação desenvolvida ao longo do tempo, através das relações entre o filme e o público. Os modos de endereçamento de um programa têm relações com as formas de interpelação do público. Nesta seara, cabe ressaltar que o estilo de um programa e a posição do sujeito espectador são importantes ao falarmos de modos de endereçamento Como diz a autora (2001, p.15): "Da mesma forma, existe uma 'posição' no interior das relações e dos interesses de poder, no interior das 


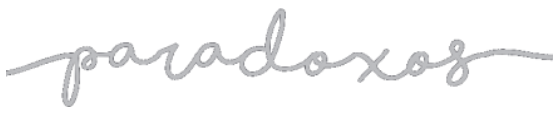

0 relato testemunhal na cobertura

do Jornal Hoje à tragédia de Brumadinho:

reflexões a partir dos modos de endereçamento.

NEGRINI, REDÜ, 2021

construções de gênero e de raça, no interior do saber, para a qual a história e o prazer visual do filme estão dirigidos".

As relações de um programa com sua audiência são demarcadas por Gomes (2007) como sendo ligadas aos modos de endereçamento. Negrini analisa o pensamento de Gomes sobre o assunto:

A autora toma o conceito de modos de endereçamento na perspectiva do modo como um determinado programa se relaciona com o público a partir da construção de um estilo próprio de transmissão de informações. Um modo de dizer específico é voltado para determinados receptores. O estilo do texto leva à constituição do sujeito receptor implícito (NEGRINI, 2018, p.110).

Modo de endereçamento pode ser apontado como uma forma de relação de determinado programa com a sua audiência a partir da construção de um estilo. $O$ estilo assumido por um telejornal está relacionado com uma constituição de espectadores esperada. O estilo é um fator demarcador da identidade de um telejornal. Gomes (2007) aponta quatro operadores de análise de modo de endereçamento: 1- o mediador; 2- o contexto comunicativo; 3- o pacto sobre o papel do jornalismo; 4 - organização temática. Neste trabalho, estamos nos focando na observação do papel dos mediadores. A partir do pensamento de GOMES (2007), cabe inferir que eles são agentes importantes no estabelecimento das formas de relação entre um telejornal e o seu público, podem ser, no telejornalismo: apresentadores, repórteres, comentaristas, editores e cinegrafistas.

\section{Perspectivas analíticas}

O Jornal Hoje é um telejornal que, dentro da programação da Rede Globo, vai ao ar no início da tarde e que, geralmente, aborda os assuntos de forma mais leve e descontraída. De acordo com o site do telejornal, ele foi ao ar pela primeira vez no dia 21 e abril de 1971, apresentado por Léo Batista e Luís Jatobá. Desde o seu princípio, tem a perspectiva de uma revista eletrônica, trazendo na pauta temas como arte espetáculos e entrevistas ${ }^{3}$. Geralmente, as edições do Jornal Hoje

\footnotetext{
${ }^{3}$ Fonte: http://g1.globo.com/jornal-hoje/noticia/2010/04/historia-do-jornal-hoje.html. Acesso em 19 de dezembro de 2019.

DOI: http://doi.org/10.14393/par-v6n1-2021-55873 - Paradoxos, Uberlândia, v. 6, n. 1, p. 143-159, jan./jun. 2021| 150
} 


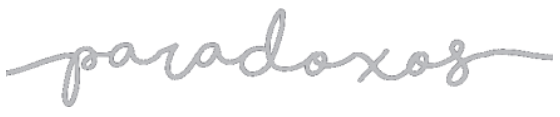

0 relato testemunhal na cobertura do Jornal Hoje à tragédia de Brumadinho: reflexões a partir dos modos de endereçamento.

NEGRINI, REDÜ, 2021

possuem de 30 a 60 minutos de duração. No dia seguinte à tragédia de Brumadinho, a edição ficou mais de duas horas e meia no ar. E em um telejornal focado em transmitir pontos relativos a uma tragédia, os relatos testemunhais são importantes e ajudam a esclarecer os fatos. Desta forma, como já falamos, o foco deste trabalho é analisar o papel dos mediadores (GOMES, 2007) na edição em seu trabalho de captação dos relatos testemunhais. Vale ressaltar que os mediadores (GOMES, 2007) dão bases para que se materialize o estilo do telejornal. Vamos observar os primeiros trinta minutos do programa.

\section{Testemunhas explicando a tragédia}

Ainda na primeira reportagem da edição do dia 26 de janeiro, que foi focada na narração de como aconteceu o rompimento, é ressaltado pela repórter Aline Aguiar: "os moradores tentavam entender o que acontecia" (04m:58s), demonstrando que a voz dos moradores é primordial no resgate aos fatos ocorridos e na narração deles. Como falamos anteriormente, através do pensamento de Motta e Amaral (2016), nos primeiros dias de cobertura, os relatos das testemunhas são fundamentais nas coberturas jornalísticas.

Na reportagem, em off, cobrindo imagens de muita lama passando, a voz de uma pessoa local salienta: "Não sei o que aconteceu, mas tá com cara de que alguma barragem aqui estourou. É muita coisa descendo, muita coisa..." (05m:01s). Neste ponto, cabe salientar as opções de mediadores como a repórter e o editor em casar o relato da testemunha com as imagens de lama, casando a voz de quem testemunhou o fato com imagens do acontecimento. O casamento da imagem com o relato reitera sentidos de destruição e de acontecimento devassador.

Na mesma reportagem, um rapaz, todo sujo de lama, relata: "Tenho familiares aqui que trabalham na pousada. Levou tudo, não sobrou nada. Então, quem tava trabalhando ali... [...] tem meu irmão" (05m:34s). O rapaz é enquadrado do peito para cima na maior parte do tempo em que é mostrado. Por ele ter parente desaparecido, ele se torna uma fonte com informações ricas e que pode acrescentar perspectivas de sensibilidade ao relato da reportagem. Lembrando que Amaral (2013a) aponta que as 


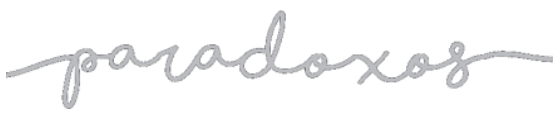

0 relato testemunhal na cobertura do Jornal Hoje à tragédia de Brumadinho: reflexões a partir dos modos de endereçamento.

NEGRINI, REDÜ, 2021

fontes testemunhais trazem a marca do sensível a uma reportagem. Cabe ressaltar que durante a fala da fonte, a repórter indaga: "está desaparecido? (05m:42s)". E o rapaz confirma: “Tá desaparecido" (05m:44s). A repórter faz uma mediação no relato do entrevistado para ele dar mais informações em sua fala e para dar ênfase ao fato dele estar falando de um lugar de parente de vítima, com propriedade para demonstrar seus sentimentos sobre o fato.

Como mostra a FIGURA 1, ao fundo da imagem com o rapaz, aparecem dois homens, sendo que um tem a bermuda suja. Demonstrar personagens que não estão limpos é uma opção do repórter e da equipe de edição do telejornal para reiterar que estas pessoas podem dar relatos fidedignos, diretamente do local do acontecimento, e que estão emergidas na seara da tragédia.

FIGURA 1 - Testemunha falando sobre a tragédia.

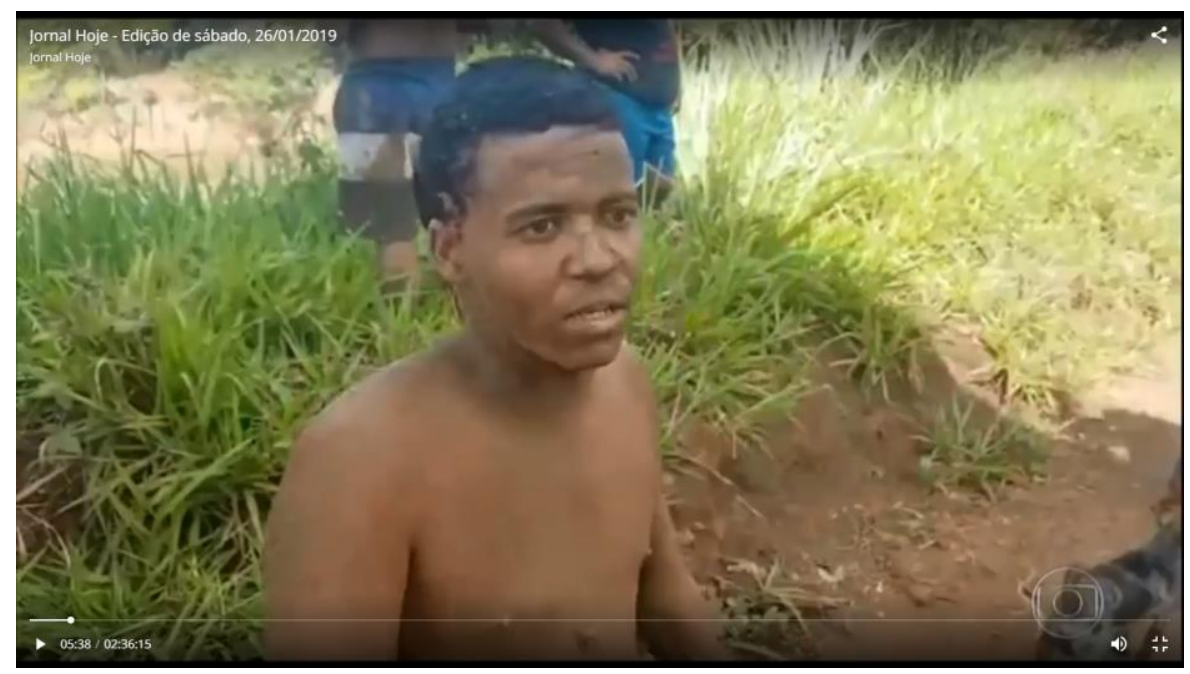

A repórter, para trazer ao contexto da reportagem uma outra fonte testemunhal, salienta: "A Keli, que tem um filhinho de seis meses, trabalha perto de uma fazenda e estava no caminho da lama. Ela e o bebê conseguiram escapar" (06m:04s). A testemunha profere palavras no sentido de narrar o que viu no momento da tragédia: "E a menina ficou pra trás... e eu gritando... ficou presa debaixo de uns negócios que caíram em cima da perna dela [...]" (06m:13s). Neste testemunho, cabe salientar o papel do cinegrafista, que capta a imagem mais fechada no rosto de Keli, depois faz uma abertura na imagem, enfocando a moça e 


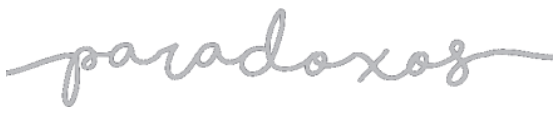

0 relato testemunhal na cobertura

do Jornal Hoje à tragédia de Brumadinho: reflexões a partir dos modos de endereçamento.

NEGRINI, REDÜ, 2021

uma senhora com uma criança no colo, e ainda faz uma imagem percorrendo o corpo da moça, mostrando que ela estava com roupas sujas. O trabalho do cinegrafista dá subsídios para reiterar as dimensões de expansão da lama, atingindo as pessoas que estavam nas redondezas.

Ainda na reportagem, a espera dos parentes é enfocada. "Tenho primos, amigos, a minha afilhada também. São várias pessoas aqui da comunidade e, também, conhecidos nossos, né. Aí a gente está aqui, aguardando qualquer notícia, independente de qual seja a notícia, a gente está aqui para isso" (06m:44s). Neste caso, o relato testemunhal dá perspectivas das dimensões do ocorrido e da abrangência da destruição, deixando muita gente morta e causando abalo nas pessoas da região. Cabe salientar que a repórter teve papel importante na montagem da matéria, colocando a fala desta fonte para ilustrar a angústia dos sobreviventes da região.

Ao falar das buscas e do transporte de corpos de vítimas pelos helicópteros, um homem é trazido para a narrativa para contar o que está presenciando. A repórter, em off cobrindo imagens do sujeito falando, enfatiza que ele ficou apreensivo, mas também aliviado. Ela acrescenta que ele se sente aliviado por ser um dos sobreviventes e angustiado pelo fato de alguns amigos continuarem desaparecidos. $\mathrm{O}$ depoimento do homem reitera as informações da repórter: "Sou sim... um sobrevivente. Eu agradeço a minha vida hoje a Deus. Minha família, cara, tudo me esperando em casa. Quando eu cheguei, foi a coisa mais importante na minha vida que eu vi meus netos, meus filhos. Hoje eu poderia estar de baixo de um barro desses ..." (07m:24s). A repórter deu voz à testemunha, que também foi sobrevivente da tragédia, e deixou ela fazer um relato do que viveu no dia, demonstrando que a reportagem está focada na demonstração das sensibilidades para narrar as experiências.

\section{Procura por desaparecidos}

Vamos observar, também, relatos de pessoas que foram convocadas ao JH e que estavam procurando por desaparecidos na tragédia. Apesar de não terem estado nas redondezas da ocorrência da tragédia, eles trazem relatos, na maior parte dos casos, 


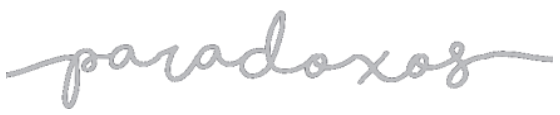

0 relato testemunhal na cobertura do Jornal Hoje à tragédia de Brumadinho: reflexões a partir dos modos de endereçamento.

NEGRINI, REDÜ, 2021

cheios de emotividade, que ajudaram a contar a tragédia ao espectador. Por isso, optamos por analisá-las também.

Em matéria sobre famílias buscando os desaparecidos em Brumadinho, a repórter Cristiane Leite começa o off introduzindo o relato de uma moça destacando a emotividade da fonte. A entrevistada relata: "Eu tenho esperança que ele está vivo. Mas nosso primo, ele já tinha quase 60 anos, não tem destreza para correr. O local que ele estava trabalhando ninguém sabe. Ele trabalhava com encanamento, então, onde tinha um problema, ele ia. Nós não sabemos o local, a localização nem pra pedir pra olhar próximo, né. Então, assim, a gente fica numa angústia" (13m:08s). Cabe apontar que o relato é longo e que, na edição, poderia ter sido mostrado de forma mais breve, mas se verifica a opção da repórter e da equipe de edição em mostrar uma fala mais longa e com mais detalhes sobre a busca de um desaparecido. Neste caso, cabe assinalar também o papel do cinegrafista que captou a imagem em um plano mais fechado, como mostra a FIGURA 2, ficando bem evidente que a fonte estava muito emocionada e triste.

FIGURA 2 - Parente de vítima

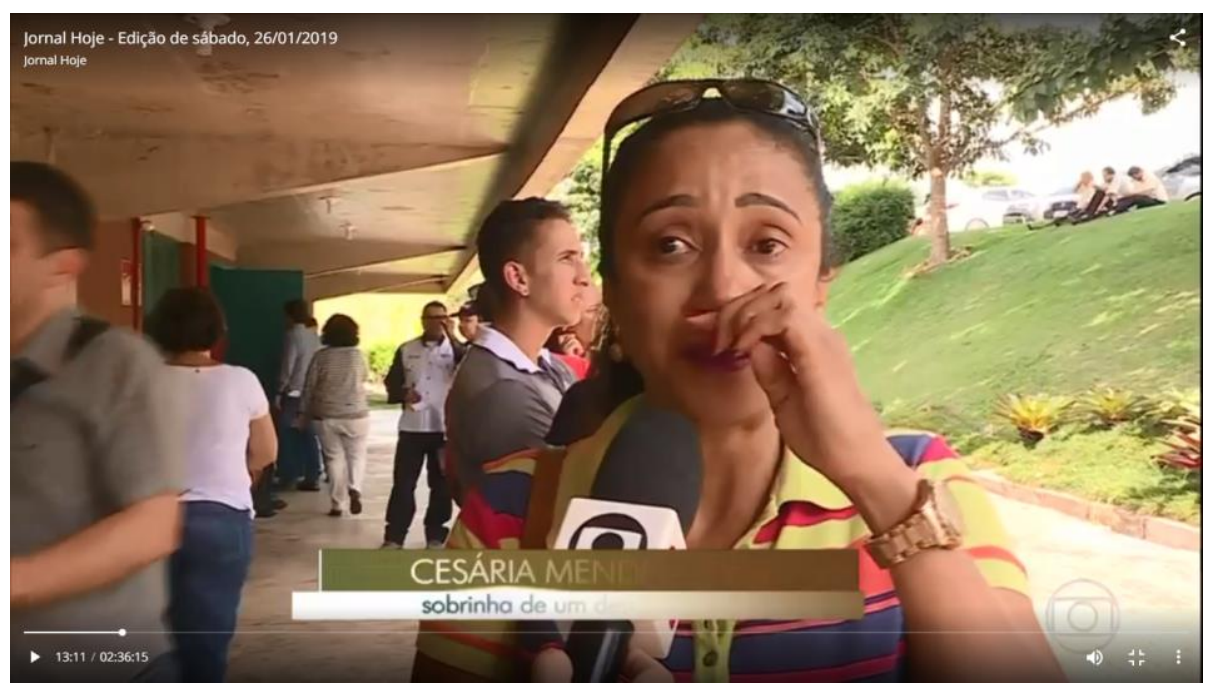

$\mathrm{O}$ enquadramento de uma imagem que demonstra a tristeza de uma fonte demarca que a edição especial do telejornal fugiu ao estilo mais leve e mais descontraído que o que ele normalmente assume e enfatiza que os modos de 


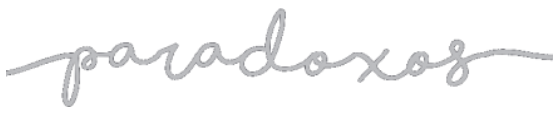

0 relato testemunhal na cobertura

do Jornal Hoje à tragédia de Brumadinho: reflexões a partir dos modos de endereçamento.

NEGRINI, REDÜ, 2021

endereçamento da edição estão focando um público amplo, o qual busca informações diversas sobre a tragédia.

A repórter informa, em off, que um engenheiro elétrico que estava no refeitório da empresa falou com a família minutos antes do soterramento. Ela ressalta que o homem que estava na empresa tem dois filhos adolescentes. Já neste off, cabe apontar que a repórter introduz o relato de uma fonte marcando o estilo de reportagem focado na demarcação de sensibilidade e humanidade. Ao falar que uma suposta vítima tem dois filhos adolescentes, há a criação de sentidos de que estes jovens podem ter ficado sem pai, o que tende a gerar a comoção do público. Após a introdução da jornalista, o depoimento de um irmão do desaparecido é enfocado: "E pior que nós não temos esperança nenhuma. [...] A família está toda louca" (13m:50s). O relato corrobora para os sentidos enfocados no off de perda familiar e de tristeza.

"As fotos de Tancredo com a mulher Elizabeth mostram momentos felizes do casal. Os dois estavam na mina na hora do rompimento da barragem. Tancredo estava num ponto mais elevado. Já Elizabeth trabalhava no refeitório. Ele conseguiu fugir, mas não falou mais com a esposa" (14m:04s), com estas palavras em off, a repórter introduz a fala de um homem que vivenciou a tragédia. No off, ao falar em momentos felizes do casal, a repórter constitui sentidos de que eles tinham uma relação boa e com felicidade, dando uma perspectiva emocional à narrativa, que chama atenção do público e que pode gerar comoção.

Cabe assinalar, como mostra a FIGURA 3, o homem mexendo no celular e mostrando fotos do casal, que pode ter tido a condução da repórter no decorrer da cena de apresentação do celular, pois não é postura comum de uma fonte mexer no celular e mostrar arquivos durante entrevista. Neste ponto, cabe também evidenciar o papel do cinegrafista em fazer imagens mais fechadas das imagens contidas no celular. As posturas da repórter e do cinegrafista acentuam a perspectiva de que o estilo da edição especial do JH é voltado à demonstração de emoções e de sensibilidades.

DOI: http://doi.org/10.14393/par-v6n1-2021-55873 - Paradoxos, Uberlândia, v. 6, n. 1, p. 143-159, jan./jun. 2021| 155 


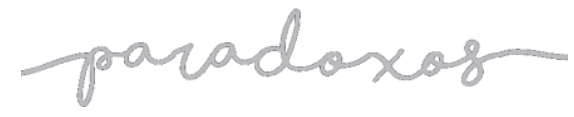

0 relato testemunhal na cobertura do Jornal Hoje à tragédia de Brumadinho: reflexões a partir dos modos de endereçamento.

FIGURA 3 - Imagem de desparecida com o marido.

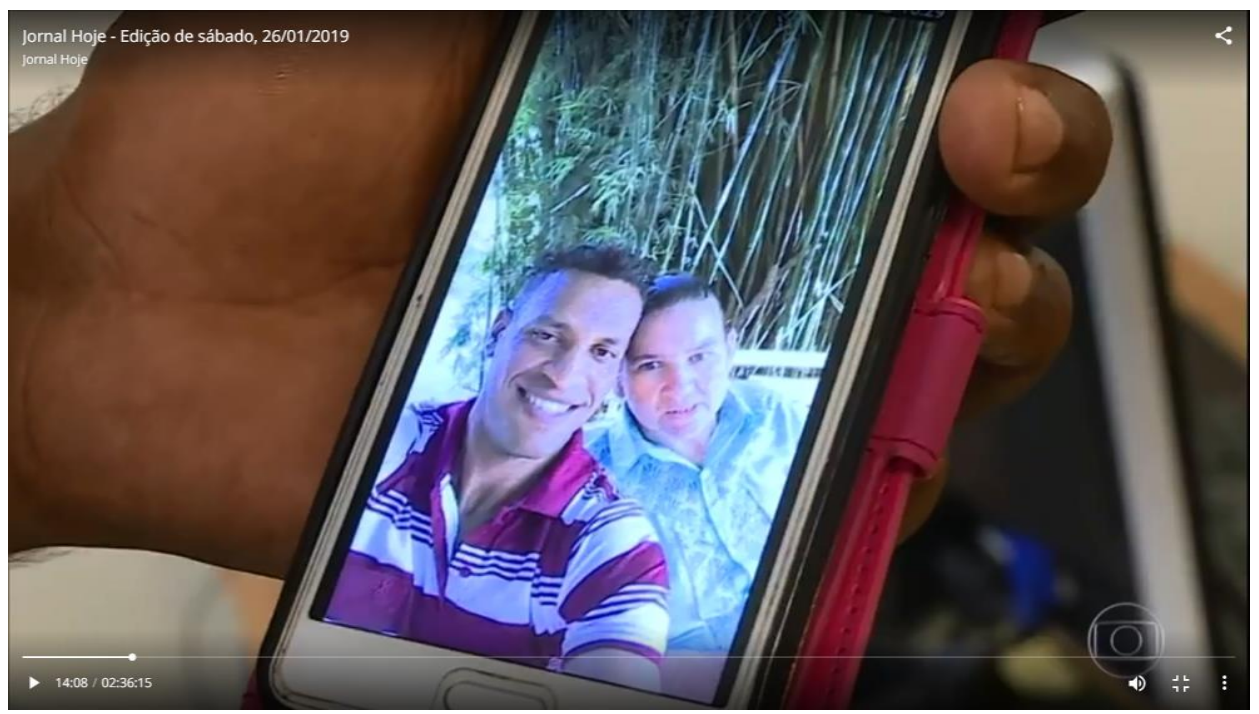

"O que dói é a gente imaginar como é que foi a reação [...]. Se ela conseguiu respirar, o sufoco que estava passando. Isso dói muito” (14m:22s), diz o marido de Elizabeth. Nas palavras selecionadas pela repórter para serem parte da reportagem, fica visível que a narrativa está sendo conduzida para levar ao público as tristezas dos sobreviventes.

É enfatizado na reportagem que alguns parentes de desaparecidos fizeram buscas por conta própria. Neste momento, a repórter diz que o colega jornalista Diego Sarza conversou com o irmão de um funcionário da Vale que tentou procurá-lo com o uso do GPS do celular. Durante a fala de Diego com este irmão, o jornalista questiona se eles moram em Brumadinho também. A resposta é negativa e é ressaltado por parte do entrevistado que tem certeza que o irmão está vivo e que tem esperanças. Isso mostra que o JH enuncia em uma perspectiva de mostrar ao público que entre a tragédia ainda há esperanças.

Cabe apontar ainda que a jornalista enfatiza a perspectiva de dor diante da tragédia em meio às famílias e que essa dor é um elo: “Centenas de famílias estão unidas pela dor. Elas esperam por informações na estação do conhecimento da Vale, onde são feitos os cadastros dos desaparecidos. A defesa civil já tem uma lista com páginas e mais páginas. Ainda não há um número consolidado, considerando também os moradores da região" (15m:14s). 


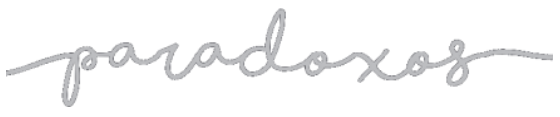

0 relato testemunhal na cobertura

do Jornal Hoje à tragédia de Brumadinho:

reflexões a partir dos modos de endereçamento.

NEGRINI, REDÜ, 2021

No destaque aos elos gerados pela tragédia, os relatos dos que foram ao local para ajudar também ganham espaço. “Comida, lava, dá banho, precisar de uma palavra de conforto, né. Uma palavra amiga. Um abraço. [...] A gente tá aqui é pra isso. Minha família está segura, mas tem outros que estão precisando da gente aqui” (15m:57s). O tom voltado ao destaque às sensibilidades geradas pela tragédia demonstra que o repórter, em sua função de mediador, fez um recorte voltado à demonstração de afetos e de tristezas na retratação da procura por desaparecidos.

No decorrer da edição, uma entrevista do repórter Danilo Girundi com David, o marido de uma vítima que foi retirada da lama com vida, sentindo muita dor e muito desespero, infere que os mediadores do programa estão fazendo a cobertura do fato com foco em salientar os aspectos humanos que se mostram em uma tragédia.

\section{Algumas considerações}

A realização de coberturas jornalísticas de tragédias é uma atividade dotada de complexidades e que exige muito dos jornalistas e de toda a equipe de uma redação. São os mediadores, como repórteres, cinegrafistas e apresentadores, que se deparam com a difícil tarefa de levar ao público informações de um tema que gera tristezas nos espectadores.

Em relação à tragédia de Brumadinho, equipes de redação ficaram frente a um acontecimento que devastou o meio ambiente e que ceifou vidas, gerando mobilização em todo o país e no exterior para a busca pelos corpos dos falecidos e para ajudar os sobreviventes. Desta forma, a realização da atividade jornalística ficou permeada pela difícil tarefa de lidar com a dor humana e com a morte.

As falas das testemunhas de tragédias são primordiais para as primeiras coberturas após um acontecimento. E, no caso de tragédias, os que presenciaram um fato podem dar informações que são primordiais para o esclarecimento do ocorrido. Neste artigo, focamos na observação do trabalho dos mediadores do Jornal Hoje na captação de relatos testemunhais na edição especial do telejornal, que foi ao ar no dia 26 de janeiro de 2019. Como a edição teve mais de duas horas de duração, concentramos o olhar nos primeiros trinta minutos do programa.

DOI: http://doi.org/10.14393/par-v6n1-2021-55873 - Paradoxos, Uberlândia, v. 6, n. 1, p. 143-159, jan./jun. 2021| 157 


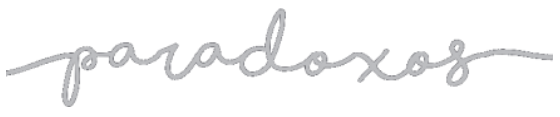

0 relato testemunhal na cobertura

do Jornal Hoje à tragédia de Brumadinho: reflexões a partir dos modos de endereçamento.

Como já mencionado, o Jornal Hoje é conhecido por ser um telejornal mais leve e que apresenta assuntos de forma mais descontraída. Porém, destacamos que a edição do dia seguinte à tragédia de Brumadinho fugiu ao estilo normalmente visualizado no programa e assumiu um estilo voltado a demonstração do drama dos sobreviventes e da região do fato, além da tristeza gerada. No dia, o estilo assumido pelo telejornal foi concentrado em atingir um grande público, o qual estava na busca de mais informações sobre a tragédia de Brumadinho.

E para a constituição de tal estilo, os mediadores tiveram papel importante, tanto na constituição das narrativas, como na captação de informações das testemunhas da tragédia. Na captação dos relatos testemunhais, cabe destacar que os mediadores deram ênfase à demonstração do lado humano que envolve uma tragédia e à transmissão de sensibilidades. As fontes foram convocadas para narrar suas experiências com o que viveram, mas também para demonstrar suas sensações e suas dores. E esta postura serviu como um elo entre o grande público e o programa, gerando proximidade.

\section{Referências}

AMARAL, Márcia Franz. Os testemunhos de catástrofes nas revistas brasileiras: do medo individual à patemização midiática. In: Revista Contracampo, v. 26, n. 1, ed. abril, ano 2013. Niterói: Contracampo, 2013a. Pags: 71-86. DOI:

https://doi.org/10.22409/contracampo.v0i26.260.

AMARAL, Márcia Franz. A representação dos testemunhos no discurso das catástrofes ambientais: de sujeitos sociais a sujeitos discursivos. In: Revista Fronteiras - Estudos Midiáticos, v. 15, n. 3, p. 182-190, setembro-dezembro de 2013b. DOI: https://doi.org/10.4013/fem.2013.153.04.

COUTINHO, Iluska; MATA, Jhonatan. A atuação do repórter na cobertura televisiva de tragédias: o olhar do jornalista como testemunha do fato que enuncia. Estudos em Jornalismo e Mídia, v. 10, p. 379-398, 2013. DOI: https://doi.org/10.5007/1984-6924.2013v10n2p379.

ELLSWORTH, Elizabeth. Modos de Endereçamento: uma coisa de cinema; uma coisa de educação também. In: SILVA, Tomaz Tadeu da. Nunca fomos humanos - nos rastros do sujeito (org e trad), Belo Horizonte: Autêntica, 2001.

EMERIM, Carlida; BRASIL, Antonio. Coberturas em telejornalismo. In: XXXIV Congresso Brasileiro de Ciências da Comunicação, 2011, Recife. Anais. Recife: Intercom, 2011.

DOI: http://doi.org/10.14393/par-v6n1-2021-55873 - Paradoxos, Uberlândia, v. 6, n. 1, p. 143-159, jan./jun. 2021| 158 
EVANGELISTA, Renata. Tragédia em Brumadinho completa oito meses com 249 mortos, 21 desaparecidos e nenhum preso. Disponível em: https://www.hojeemdia.com.br/horizontes/trag\%C3\%A9dia-em-brumadinho-completaoito-meses-com-249-mortos-21-desaparecidos-e-nenhum-preso-1.744992. Acesso em 30 de setembro de 2019.

GOMES, Itania. Questões de método na análise do telejornalismo: premissas, conceitos, operadores de análise. Revista ECompós, Porto Alegre, v.18, no. 1, p. 111130, janeiro - abril de 2007. DOI: https://doi.org/10.30962/ec.v8i0.126.

JORNAL HOJE. História do Jornal Hoje. Disponível em: http://g1.globo.com/jornalhoje/noticia/2010/04/historia-do-jornal-hoje.html. Acesso em 19 de dezembro de 2019.

MAIA, Marta Regina; BARRETOS, Dayane do Carmo. O testemunho como elemento central na produção jornalística: a narrativa de "Operação massacre". Rizoma, Santa Cruz do Sul, v. 6, n. 1, p. 214-226, agosto, 2018. DOI: https://doi.org/10.17058/rzm.v6i1.11550.

MORAES, Thiago. Escalada: as manchetes de um telejornal. Disponível em: http://www.casadosfocas.com.br/escalada-as-manchetes-de-um-telejornal/. Acesso em 11 de junho de 2021.

MOTTA, Juliana; RUBLESCKI, Anelise. Cobertura ao vivo em televisão: o improviso e o testemunho em situações de tragédia. In: V Seminário Internacional de Pesquisa em Comunicação - Sipecom, 2013, Santa Maria. Epistemologia e desafios da pesquisa no campo da Comunicação. Santa Maria: Programa de Pós-Graduação em Comunicação, 2013. v. 1. p. 1-15.

MOTTA, Juliana; AMARAL, Marcia Franz. Os testemunhos na cobertura jornalística do caso Kiss: transbordamento emocional e provas de verdade. Estudos em Jornalismo e Mídia, Florianópolis, v.13, no. 1, p. 77-88, janeiro - junho/2016. DOI: https://doi.org/10.5007/1984-6924.2016v13n1p77.

NEGRINI, Michele. Telejornalismo em análise: considerações sobre gênero televisivo e modos de endereçamento. Aturá Revista Pan-Amazônica de Comunicação, Palmas, v. 2, n. 1, p. 99-119, jan-abr. 2018.

RODRIGUES, Adriano Duarte. Comunicação e experiência. Disponível em: http://www.bocc.ubi.pt/pag/rodrigues-adriano-comunicacao-experiencia.pdf. Acesso em 30 de setembro de 2019.

SOUZA, Felipe; FELLET, João. Brumadinho pode ser $2^{\circ}$ maior desastre industrial do século e maior acidente de trabalho do Brasil. Época. Disponível em: https://epocanegocios.globo.com/Brasil/noticia/2019/01/brumadinho-pode-ser-2-maiordesastre-industrial-do-seculo-e-maior-acidente-de-trabalho-do-brasil.html. Acesso em: 30 de agosto de 2019.

WHITE, Ted. Jornalismo eletrônico: redação, reportagem e produção. 4a. Ed. São Paulo: Roca, 2008. 